\title{
Avaliação físico-química dos óleos de babaçu (Orbignya speciosa) e coco (Cocos nucifera) com elevado índice de acidez e dos ácidos graxos (C6 a C16)
}

\begin{abstract}
Physical-chemical evaluation of babassu oil (Orbinya speciosa) and coconut oil (Cocos nucife)
\end{abstract} with high acidity and fatty acids (C6 to C16)

\author{
F. A. F. da Ponte' ${ }^{1}$; J. S. Rodrigues²; J. Q. Malveira²; J. A. S. Ramos Filho'; M. C. \\ G. Albuquerque $3^{*}$ \\ ${ }^{1}$ Departamento de Engenharia Química/bloco 709, Universidade Federal do Ceará, 60455-760, Fortaleza-Ce, Brasil \\ ${ }^{2}$ Núcleo de Tecnologia Industrial do Ceará-NUTEC, 60451-970, Fortaleza-Ce, Brazil \\ ${ }^{3}$ Departamento de Engenharia Mecânica/bloco 714, Universidade Federal do Ceará, 60455-760, Fortaleza-Ce, Brasil
}

*monica.albuquerque@ufc.br

(Recebido em 25 de fevereiro de 2016; aceito em 25 de agosto de 2017)

\begin{abstract}
Os óleos vegetais apresentam diversas aplicações em processos industriais e por isto tem aumentado constantemente a demanda na utilização de óleos de baixa qualidade, principalmente na produção de biocombustível. O presente trabalho teve por objetivo a avaliação físico-química dos óleos de babaçu (Orbinya speciosa) e coco (Cocos nucifera) de baixa qualidade, como também a obtenção dos ácidos graxos livres de 6 a 16 átomos de carbonos com finalidade de serem utilizados como matéria-prima para a produção de biocombustível. O óleo de babaçu e de coco, como também os ácidos graxos obtidos destes óleos foram caracterizados quanto as suas propriedades físico-químicas e composição em ácidos graxos (utilizando a cromatografia gasosa acoplado à massa). A técnica de RMN foi utilizada para demonstrar a eficiência da destilação fracionada a pressão reduzida na obtenção dos ácidos graxos de cadeia carbônica intermediaria. Os resultados obtidos demonstraram que a baixa qualidade, em termos de avaliação físico-química dos óleos de babaçu e coco interferem diretamente na aplicação industrial, entretanto, estes ácidos graxos podem ser utilizados em cosmético, produtos farmacêuticos e principalmente na produção de combustível, como o bioquerosene. As análises cromatográficas mostraram ainda, que os óleos de babaçu e coco apresentam como ácidos graxos majoritários o ácido láurico (57,5 e 38,6\%, respectivamente), enquanto que a fase de topo da destilação do óleo de coco apresentou o ácido caprílico $(39,1 \%)$ como principal ácido graxo.

Pala-chave: óleo de babaçu (Orbinya speciosa), óleo de coco (Cocos nucifera), ácidos graxos C6 a C16
\end{abstract}

The vegetable oils have many applications in industrial processes and due to this potential has constantly increased the demand in the use of low quality oils, mainly in the production of biofuel. This work aims to physicochemical evaluation of babassu oil (Orbinya speciosa) and coconut (Cocos nucifera) of low quality, as well the obtaining the free fatty acids 6 to 16 carbon atoms, with intention to be used as raw material for the biofuels production. The babassu oil and coconut low quality, as well the fatty acids obtained from these oils were characterized as their physicochemical properties and fatty acid composition (using gas chromatography coupled to mass). The NMR technique was used to assess the efficiency of fractional distillation under reduced pressure to obtain the intermediate carbonic chain fatty acids. The results showed that the bad quality in terms of physicochemical evaluation of babassu oils and coconut oils interfere directly in industrial application. However the fatty acids of intermediate carbonic chain (C6 to C16) may be used in cosmetic, pharmaceutical and particularly as the biokerosene fuel. The chromatographic analysis showed that the babassu oil and coconut oil have as major fatty acids are lauric acid (57.5 and 38.6\%, respectively), whereas the top phase from distillation of coconut oil showed caprylic acid $(39.1 \%)$ and major fatty acid.

Keywords: babassu oil (Orbinya speciosa), coconut oil (Cocos nucifera), fatty acids C6 to C16

\section{INTRODUÇÃO}

A constante busca por produtos de baixo custo e que sejam renováveis, biodegradáveis e ambientalmente corretos, tem levado a humanidade a utilizar os óleos vegetais em diversos 
processos industriais. O Nordeste brasileiro possui uma extensa área propícia ao cultivo de oleaginosas para a produção de óleos vegetais.

Dentre as diversas fontes renováveis de biomassa utilizados na indústria, principalmente no setor alimentício, destacam-se as palmeiras, babaçu (Orbinya speciosa) e coqueiro (Cocos nucifera) [1]. Estas frutífeiras, em modo geral, possuem óleos de composições químicas bastante semelhantes, como é o caso da amêndoa de babaçu e a polpa do coco que são compostas por mais de 60\% de óleo, predominantemente de ácidos graxos de cadeia carbônicas intermediárias (C6 a C16), dentre os quais 40 a 55\% é de ácido láurico, que corresponde a 12 átomos de carbono na sua constituição [2,3]. Este ácido, ao contrario de outros ácidos, possui apenas ligações simples entre carbonos [4]. Devido a isso é denominado de ácido saturado e exibe importância significativa nas indústrias, pois é resistente a oxidação térmica e possui baixa temperatura de fusão [5].

Das regiões brasileiras com maior exploração econômica destas biomassas, destaca-se a região nordeste, principalmente os estados do Maranhão (MA), Piauí (PI) e Ceará (CE) [6]. Os óleos de babaçu e do coco são largamente utilizados na indústria de cosméticos e alimentos. Entretanto, amêndoas de babaçu, bem como o fruto do coco ao serem estocados por muito tempo e expostos ao ar úmido tornam os óleos destas matérias primas rançosos, pela ação de enzimas que os acidificam, quebrando os triglicerídeos em ácidos graxos livres e tornando-os impróprios para a produção nestes setores $[7,8,9]$. Uma solução de aplicação para estes tipos de óleos seria no setor de combustível.

Diante da importância das biomassas de babaçu e coco no panorama econômico regional e tendo em vista a escassez de pesquisa enfocando óleos de qualidade indesejável para as indústrias, objetivou-se por meio do presente trabalho a obtenção e avaliação físico-química dos ácidos graxos livres de 6 a 16 átomos de carbonos que foram obtidos através da técnica de destilação fracionada a pressão reduzida dos óleos de babaçu e de coco, com finalidade deste serem matéria prima para a produção de biocombustível.

\section{MATERIAL E MÉTODOS}

Para a realização deste trabalho foram utilizados óleos vegetais de babaçu com um nível de acidez de 22,3 $\mathrm{mg} \mathrm{KOH} \mathrm{g}^{-1}$ que estava em estoque deste 2007 adquirido da empresa TOBASA pelo Laboratório de Referências em Biocombustível Prof. Expedito José de Sá Parente da Fundação Núcleo de Tecnologia Industrial do Ceará (LARBIO - NUTEC) e o óleo de coco fornecido pela empresa DUCOCO com um nível de acidez de 232,4 $\mathrm{mg} \mathrm{KOH} \mathrm{g}^{-1}$.

\subsection{Reação de hidrolise do óleo de babaçu}

Com o intuito de melhorar o rendimento na obtenção dos ácidos graxos de cadeia carbônica intermediária (C6 a C16) do óleo de babaçu. Realizou-se uma reação de hidrólise para aumentar a quantidade de ácido graxo livre no óleo de babaçu, de acordo com o procedimento relatado no trabalho de Patil et al. (1988) [10].

\subsection{Obtenção dos ácidos graxos}

A separação dos ácidos graxos livres na faixa de cadeia carbônica de C6 a C16 dos óleos vegetais de babaçu e de coco foram obtidos através de um sistema de destilação fracionada à vácuo no qual os ácidos graxos mais leves foram destilados na faixa de temperatura de $140^{\circ} \mathrm{C}$ a $180{ }^{\circ} \mathrm{C}$ em pressão reduzida de 0,01 bar (1,33 Kpa) como mostra a Figura 1. 


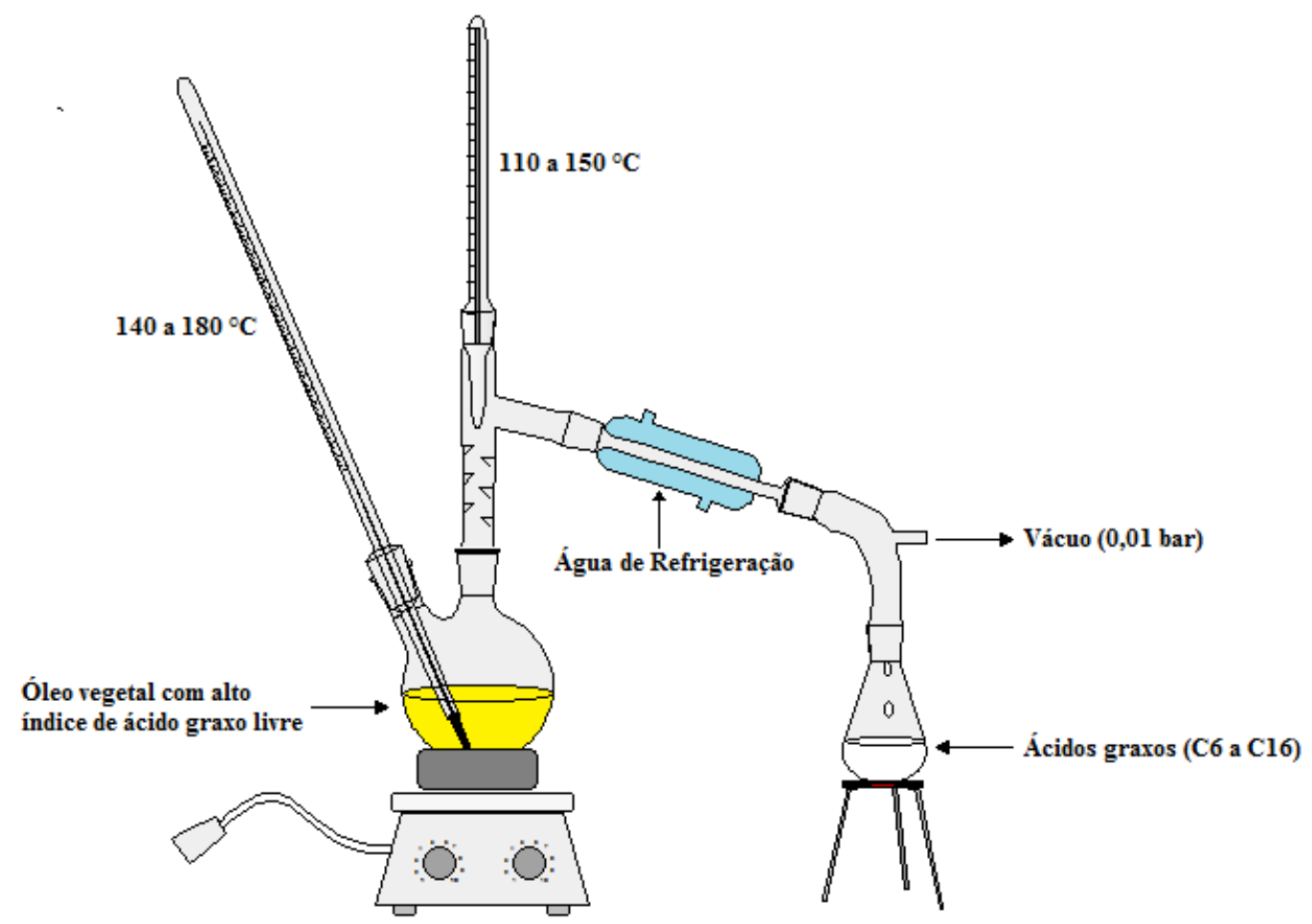

Figura 1: Sistema representativo da destilação fracionada a vácuo dos óleos vegetais.

\subsection{Caracterização dos óleos e dos ácidos graxos}

Foram realizadas as caracterizações físico-químicas dos óleos vegetais de babaçu e de coco, antes da etapa de destilação, como também, após esta etapa (fase de fundo) e dos ácidos graxos obtidos na destilação (fase de topo).

As propriedades de índice de acidez, índice de refração e índice de saponificação foram determinadas de acordo com a metodologia descrita na literatura [11]. Realizou-se ainda as seguintes caracterizações: determinação da viscosidade cinemática, que foi efetuada em um viscosímetro automático Tamson TV 2000/AKV com precisão de $0,001 \mathrm{~mm}^{2} \mathrm{~s}^{-1}$ de acordo com a norma ABNT NBR-10441 [12]. Umidade foi determinada segundo norma ASTM D-6304 [13], utilizando-se titulador coulométrico de Karl Ficher modelo $831 \mathrm{KF}$. Densidade a 15 e a $20{ }^{\circ} \mathrm{C}$, que foi determinada de acordo com a norma ABNT NBR-14065 [14], em um densímetro digital Anton Paar DMA 4500. Todas as análises foram realizadas em triplicadas.

O cálculo do desvio padrão das análises de caracterização foram determinados a partir da Equação 1.

$$
D P=\sqrt{\frac{\sum|x-x|^{2}}{n}}
$$

Onde $D P$ representa o desvio padrão da análise; $x$ é o valor numérico dos conjuntos de dados; $x$ é a média do conjunto de dados e $n$ é o números de replicadas das análises.

\subsubsection{Composição químicas das matérias-primas}

Tanto os óleos vegetais como os materiais destilados (fase de topo) foram analisados em um CG/MS QP2010 (Shimadzu, Japão) equipado com uma coluna capilar Rtx-5MS de $30 \mathrm{~m}$ de comprimento, $0,25 \mathrm{~mm}$ de diâmetro e espessura de $0,25 \mu \mathrm{m}$. O gás de arraste utilizado foi o hélio, a uma taxa de fluxo de 5,0 mL min ${ }^{-1}$. A taxa de fluxo de purga foi de $3,0 \mathrm{~mL} \mathrm{~min}^{-1}$ e a velocidade linear de $36,3 \mathrm{~cm} \mathrm{~s}^{-1}$. A temperatura foi programada como se segue: iniciou-se a $50{ }^{\circ} \mathrm{C}$, seguido de um taxa gradual de $15^{\circ} \mathrm{C} \mathrm{min}^{-1}$ até atingir $270{ }^{\circ} \mathrm{C}$ esta temperatura mantendo por 20 minutos, em 
seguida deu-se sequência a rampa de aquecimento até $300{ }^{\circ} \mathrm{C}$ com uma taxa de $10{ }^{\circ} \mathrm{C} \mathrm{min}{ }^{-1}$. A temperatura do injetor foi de $250{ }^{\circ} \mathrm{C}$ e interface de fonte de íons de $260{ }^{\circ} \mathrm{C}$.

\subsubsection{Análise de Ressonância magnética nuclear (RMN)}

A Ressonância Magnética Nuclear de Hidrogênio-1 foi utilizada para avaliar a eficiência da destilação. Para as análises, cerca de $30 \mathrm{mg}$ das amostras foram dissolvidas em clorofórmio deuterado $\left(\mathrm{CDCl}_{3}\right)$ e adicionadas ao tubo de RMN.

As amostras de óleos e ácidos graxos foram analisadas através dos espectros de Ressonância Magnética Nuclear de Prótio (RMN ${ }^{1} \mathrm{H}$ ), uni e bidimensionais, obtidos em espectrômetros Bruker, modelos Avance DRX-500 e DPX 300, pertencentes ao Centro Nordestino de Aplicação e Uso da Ressonância Magnética Nuclear da Universidade Federal do Ceará (CENAUREMN-UFC). Foram aplicadas frequências de $500,13 \mathrm{MHz}\left({ }^{1} \mathrm{H}\right)$ e $125,75 \mathrm{MHz}\left({ }^{13} \mathrm{C}\right)$, sob um campo magnético de 11,7 T para o Avance DRX-500, e $300 \mathrm{MHz}\left({ }^{1} \mathrm{H}\right)$ e $75 \mathrm{MHz}\left({ }^{13} \mathrm{C}\right)$ sob um campo de 7,05 T para o Avance DPX-300. Os experimentos foram efetuados em sonda dual de $5 \mathrm{~mm}$ com detecção direta para o Avance DPX-300 e em sonda multinuclear de $5 \mathrm{~mm}$, com detecção inversa para o Avance DRX500. Os espectros foram processados utilizando o software TopSpin versão 1.3.

\section{RESULTADOS E DISCUSSÃO}

\subsection{Propriedades físico-químicas das matérias-primas}

Os ácidos graxos são matérias primas de baixo custo e biodegradáveis, portanto excelente para a produção dos biocombustíveis. Além disso, o bioproduto proveniente desta matéria-prima pode apresentar propriedades semelhantes a dos derivados de petróleo, tais como querosene e o diesel [15].

Os resultados das análises de caracterização dos óleos de babaçu e do coco, antes da destilação a pressão reduzida, como também, após a destilação (fase de fundo) e dos ácidos graxos de 6 a 16 átomos de carbonos obtidos na destilação (fase de topo), estão mostrados na Tabela 1.

Tabela 1: Propriedades físico-químicas das biomassas utilizadas no trabalho

\begin{tabular}{|c|c|c|c|c|c|c|}
\hline \multirow{3}{*}{ Análises } & \multicolumn{6}{|c|}{ Matéria-Prima } \\
\hline & \multicolumn{2}{|c|}{$\begin{array}{l}\text { Óleo vegetal } \\
\text { (in natura) }\end{array}$} & \multicolumn{2}{|c|}{$\begin{array}{c}\text { Destilados } \\
\text { (fase de fundo) }\end{array}$} & \multicolumn{2}{|c|}{$\begin{array}{l}\text { Ácidos graxos } \\
\text { (fase de topo) }\end{array}$} \\
\hline & Babaçu & Coco & Babaçu & Coco & Babaçu & Coco \\
\hline $\begin{array}{l}\text { Índice de acidez } \\
\left(\mathrm{mg} \mathrm{KOH} \mathrm{g}^{-1}\right)\end{array}$ & $182,4 \pm 0,3$ & $232,4 \pm 0,6$ & $81,8 \pm 0,8$ & $147,7 \pm 2,4$ & $330,6 \pm 5,4$ & $323,7 \pm 3,2$ \\
\hline Índice de refração & $1,4445 \pm 0$ & $14430+0$ & $1,4552 \pm 0$ & $1,4509 \pm 0$ & $1,4388 \pm 0$ & $1,4392 \pm 0$ \\
\hline $\begin{array}{l}\text { Índice de saponificação } \\
\left(\mathrm{mg} \mathrm{KOH} \mathrm{g}^{-1}\right)\end{array}$ & $281,8 \pm 6,2$ & $272,6 \pm 19,0$ & $256,1 \pm 5,6$ & $265,9 \pm 4,1$ & $339,4 \pm 2,6$ & $337,2 \pm 7,7$ \\
\hline $\begin{array}{l}\text { Densidade a } 15^{\circ} \mathrm{C} \\
\left(\mathrm{kg} \mathrm{m}^{-3}\right)\end{array}$ & $925,5 \pm 0,1$ & $928,7 \pm 0,1$ & $924,5 \pm 1,2$ & $920,1 \pm 0,2$ & $904,8 \pm 0,0$ & $904,3 \pm 0,0$ \\
\hline $\begin{array}{l}\text { Densidade a } 20{ }^{\circ} \mathrm{C} \\
\left(\mathrm{kg} \mathrm{m}^{-3}\right)\end{array}$ & $904,7 \pm 0,0$ & $915,2 \pm 0,8$ & $905,8 \pm 0,1$ & $916,2 \pm 0,7$ & $900,9 \pm 0,0$ & $900,4 \pm 0,1$ \\
\hline $\begin{array}{l}\text { Umidade } \\
\left(\mathrm{mg} \mathrm{kg}^{-1}\right)\end{array}$ & $1124 \pm 78$ & $5700 \pm 82$ & $469 \pm 37$ & $433 \pm 46$ & $1432 \pm 66$ & $1332 \pm 36$ \\
\hline $\begin{array}{l}\text { Viscosidade a } 40{ }^{\circ} \mathrm{C} \\
\left(\mathrm{mm}^{2} \mathrm{~s}^{-1}\right)\end{array}$ & $17,94 \pm 0,1$ & $15,93 \pm 0,0$ & $21,92 \pm 0,4$ & $26,97 \pm 0,1$ & $6,62 \pm 0,2$ & $6,82 \pm 0,1$ \\
\hline
\end{tabular}

Valores expressos em média e \pm desvio padrão.

O índice de acidez do óleo de babaçu (22,3 $\left.\mathrm{mg} \mathrm{KOH} \mathrm{g}^{-1}\right)$ e do óleo de coco $\left(232,4 \mathrm{mg} \mathrm{KOH} \mathrm{g}^{-}\right.$ ${ }^{1}$ ) apresentaram valores elevados, em relação a resolução $n^{\circ} 270$ da ANVISA [16] que permite no máximo de 0,6 $\mathrm{mg} \mathrm{KOH} \mathrm{g}^{-1}$ de acidez, indicando que há muito ácido graxo livre nos óleos, tornando-se impróprio para o consumo humano. Com a utilização do procedimento da reação de 
hidrólise do óleo de babaçu, a concentração de ácido graxo livre aumentou ainda mais, saído inicialmente de 22,3 $\mathrm{mg} \mathrm{KOH} \mathrm{g}^{-1}$ para 182,4 $\mathrm{mg} \mathrm{KOH} \mathrm{g}^{-1}$, como mostra o índice de acidez na Tabela 1 para óleo vegetal in natura para babaçu. Os ácidos graxos de cadeia carbônica intermediária (C6 a C16) presentes nestes óleos podem, facilmente, ser separados através da destilação a vácuo e estes podem ser utilizados na reação de esterificação para a formação do bioquerosene como mostra o Ponte et al. (2015) [17] e a outra parte que não destilou (fase de fundo) pode ser usada na produção do biodiesel.

O índice de refração observado à temperatura de $20^{\circ} \mathrm{C}$ para destilados da fase de fundo, do coco e do babaçu apresentaram valores superiores $(1,4509$ e 1,4552, respectivamente) ao material de partida, óleos de coco e babaçu usados na destilação, (1,4430 e 14445, respectivamente) e aos dos ácidos graxos da fase de topo obtidos na destilação (1,4392 e 1,4388, respectivamente). Isso ocorreu porque o óleo é constituído de triglicerídeos que possui uma cadeia carbônica maior, logo desvia com maior ou menor intensidade os raios luminosos que os atravessam. Portanto a fase de fundo concentra-se os triglicerídeos. Enquanto a fase de topo encontra-se apenas os ácidos graxos de cadeia carbônica intermediária (C6 a C16), este pode ser utilizado para a produção de bioquerosene.

$\mathrm{O}$ índice de saponificação das amostras foram superiores aos valores preconizados pelo Codex Alimentarius International Food Standards (2015) [18], com exceção dos valores para os óleos de fase de fundo do babaçu e coco que se enquadraram à norma. O índice de saponificação é uma análise que define, aproximadamente, o tamanho médio da cadeia carbônica dos ácidos graxos presente na composição da amostra lipídica [19]. Quanto menor for o peso médio molecular dos ácidos graxos, maior será o valor do índice de saponificação. Portanto, para o valores encontrados para o índice de saponificação dos ácidos graxos (fase de topo) de babaçu e coco (339,4 e 337,2 $\mathrm{mg} \mathrm{KOH} \mathrm{g}{ }^{-1}$, respectivamente) melhor será o bioquerosene, pois as características físico-químicas se assemelharão as do querosene fóssil.

Os altos valores das propriedades de viscosidade cinemática a $40{ }^{\circ} \mathrm{C}$ e densidade a $15^{\circ} \mathrm{C}$ e a 20 ${ }^{\circ} \mathrm{C}$ dos óleos vegetais, tanto no material de partida como na fase de fundo, em relação aos valores das propriedades dos ácidos graxos obtidos do mesmo óleo na destilação, também está diretamente ligada ao tamanho da estrutura molecular dos triglicerídeos, em relação aos ácidos graxos, confirmando assim a eficiência do processo de destilação que foi utilizado para separar os ácidos graxos de cadeia carbônica intermediária.

\subsection{Análise da composição químicas das matérias-primas}

A Tabela 2 mostra a composição química do óleo de babaçu, do óleo de coco e dos ácidos graxos obtidos na destilação destes óleos.

Tabela 2: Composição química das biomassas

\begin{tabular}{|c|c|c|c|c|}
\hline \multirow{3}{*}{$\begin{array}{l}\text { Composição dos ácidos } \\
\text { graxos }\end{array}$} & \multicolumn{4}{|c|}{ Biomassa } \\
\hline & \multicolumn{2}{|c|}{$\begin{array}{l}\text { Óleo vegetal } \\
\text { (in natura) }\end{array}$} & \multicolumn{2}{|c|}{$\begin{array}{c}\text { Ácidos graxos destilados } \\
\text { (fase de topo) }\end{array}$} \\
\hline & Babaçu & Coco & Babaçu & Coco \\
\hline C6:0 Capróico & $0,2 \%$ & $0 \%$ & $4,1 \%$ & $0 \%$ \\
\hline C8:0 Caprílico & $13,7 \%$ & $1,9 \%$ & $26,0 \%$ & $39,1 \%$ \\
\hline C10:0 Cáprico & $14,7 \%$ & $3,5 \%$ & $18,0 \%$ & $15,6 \%$ \\
\hline C12:0 Láurico & $57,5 \%$ & $38,6 \%$ & $33,4 \%$ & $36,0 \%$ \\
\hline C14:0 Mirístico & $9,6 \%$ & $22,2 \%$ & $12,6 \%$ & $5,3 \%$ \\
\hline C16:0 Palmítico & $2,3 \%$ & $13,6 \%$ & $5,9 \%$ & $2,0 \%$ \\
\hline C18:0 Esteárico & $0,4 \%$ & $3,1 \%$ & $0 \%$ & $0,4 \%$ \\
\hline C18:1 Oléico & $1,4 \%$ & $13,2 \%$ & $0 \%$ & $0,8 \%$ \\
\hline C18:2 Linoléico & $0,2 \%$ & $3,9 \%$ & $0 \%$ & $0,8 \%$ \\
\hline
\end{tabular}


Os óleos de babaçu e de coco podem ser um precursor na produção do bioquerosene, pois apresentam maiores composições de ácidos graxos na faixa de C6 a C16 que corresponde a faixa de destilação do querosene fóssil, que é de C8 a C16.

Com a utilização da técnica de destilação a pressão reduzida foi possível a obtenção dos ácidos graxos nesta faixa de cadeia carbônica. Portanto, observa-se na Tabela 2 na coluna em ácidos graxos destilados (fase de topo), que a concentração de ácidos graxos capróico, caprílico e cáprico aumentaram em relação a seus materiais de origem.

A composição química da biomassa, ácidos graxos destilados (fase de topo) do óleo de babaçu, é constituída principalmente entre quatro ácidos graxos: ácido caprílico (C8) $26 \%$, ácido cáprico (C10) 18\%, ácido mirístico (C14) 12,6\% e com uma concentração majoritária do ácido láurico (C12) 33,4\%, presentes apenas ácidos graxos saturados. Já para a biomassa dos ácidos graxos destilados (fase de topo) do óleo de coco, o majoritário foi o ácido caprílico (C8) 39,1\% e contento em poucas proporções na amostra os ácidos insaturados: ácido oléico (C18:1) e o ácido linoléico (C18:2), ambos com 0,8\%. Os ácidos insaturados aparecem por apresentarem concentrações maiores no óleo de coco (in natura) do que no óleo de babaçu (in natura), e no procedimento de destilação a vácuo serem arrastados pelos os ácidos graxos de ponto de ebulição menor.

\subsection{Análise de Ressonância magnética nuclear (RMN)}

Outra maneira que pode avaliar a eficiência da destilação fracionada é a técnica de Ressonância Magnética Nuclear de Prótio (RMN-1H) como mostra as Figuras 2 e 3.

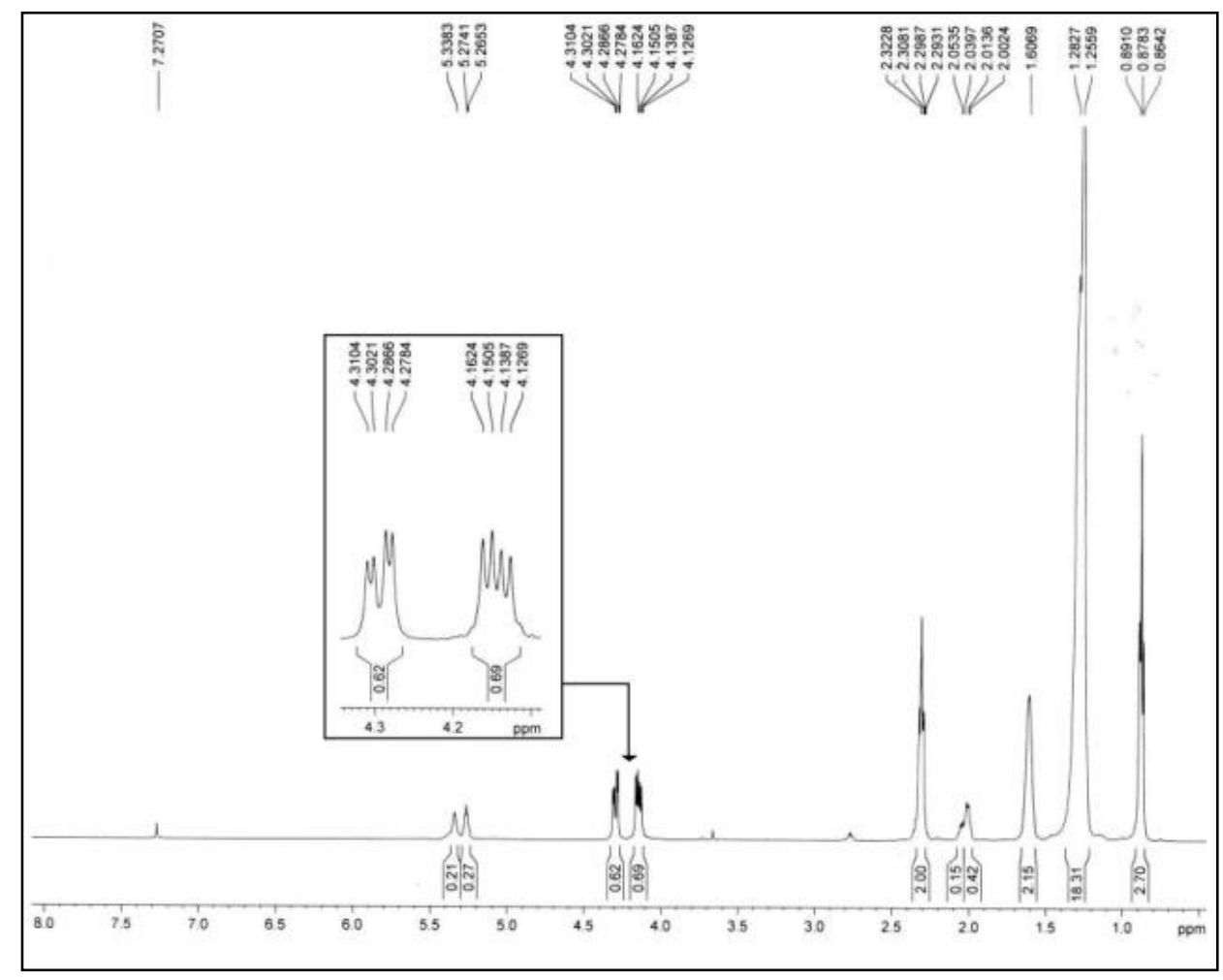

Figura 2: Espectro de RMN 1 H do óleo de babaçu in natura 


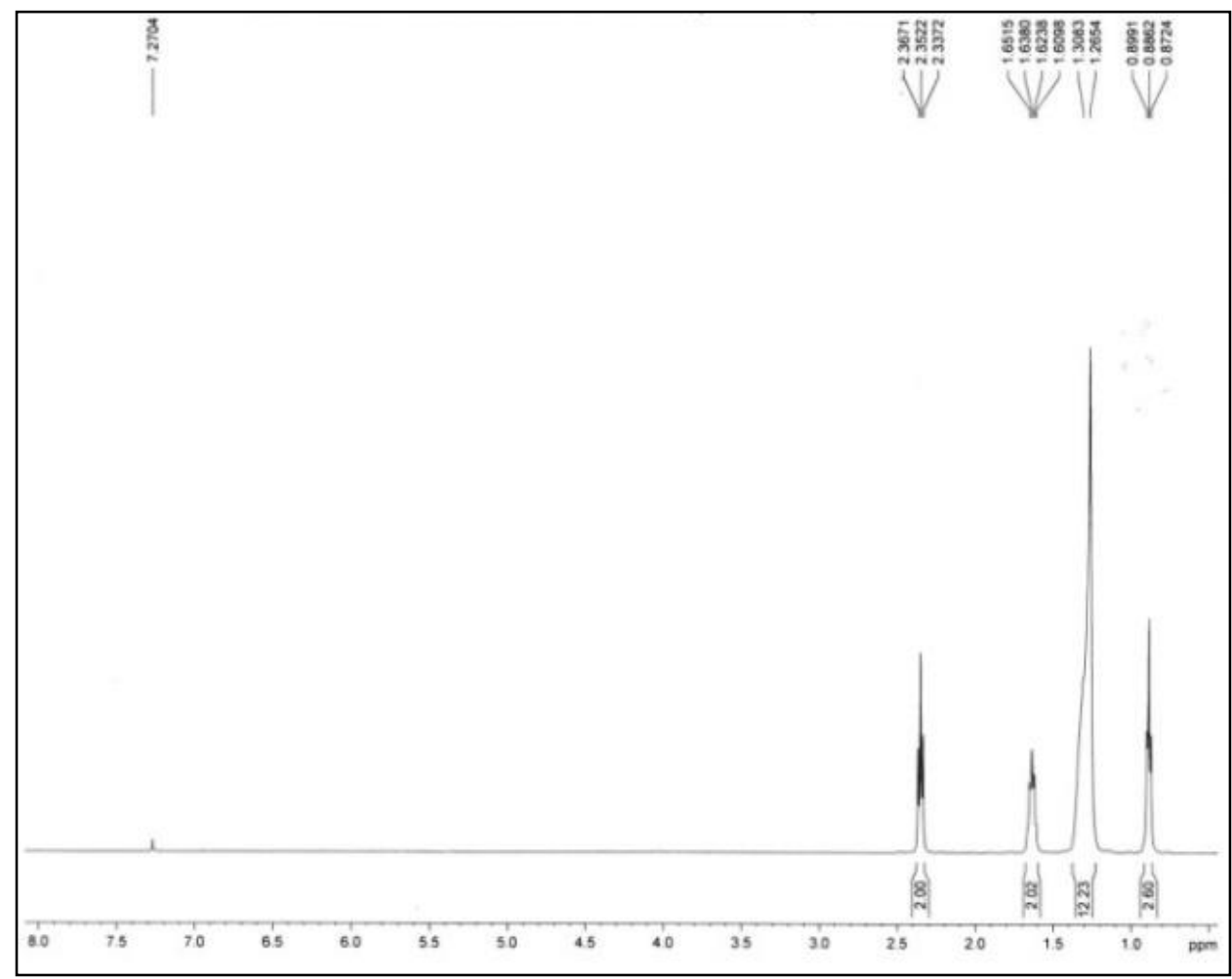

Figura 3: Espectro de RMN 1 H dos ácidos graxos de cadeias carbônicas intermediárias (C6 a C16) da fase de topo.

Comparando-se os espectros de RMN 1H das Figuras 2 e 3, observa-se que o espectro do óleo de babaçu in natura da Figura 2 apresenta, em destaque, picos na região de 4,1 a 4,3 ppm, que correspondem a átomos de hidrogênio do grupo glicerol $\left(-\mathrm{CH}_{2} \mathrm{OCOR}\right)$, e picos na região de 5,2 a $5,3 \mathrm{ppm}$, que correspondem as ligações insaturada da cadeia dos triglicerídeos do óleo de babaçu (-CH=CH-) [20, 21], e na Figura 3, nas mesmas regiões correspondentes, não há picos de prótons, principalmente na região de 5,2 a 5,3 ppm, que indica que a amostra só possui ligação simples, portanto os ácidos graxos obtidos do óleo de babaçu in natura são saturados. Confirmando os dados obtidos na cromatografia gasosa para o mesmo óleo (Tabela 2).

Os espectros mostram que a metodologia empregada para a obtenção dos ácidos graxos de cadeia carbônica intermediaria foi eficiente.

\section{CONCLUSÃO}

A partir dos estudos realizados pode-se concluir que a técnica utilizada para separar os ácidos graxos livre de 6 a 16 átomos de carbonos é satisfatória. Além disso, a avaliação físico-química dos óleos de babaçu e coco e dos ácidos graxos obtidos dos mesmos, permitem obter resultados de propriedades que servem como parâmetro de qualidade em diferentes processos industriais e desta forma direcionar a sua aplicação como matéria prima. De acordo com os resultados obtidos, conclui-se que os ácidos graxos obtidos dos óleos de babaçu e coco (fase de topo) reúnem características que possibilitam a sua aplicação como insumo na produção do bioquerosene e a parte não destilada do óleo (fase de fundo) reúnem características na produção do biodiesel.

\section{AGRADECIMENTOS}

Esta pesquisa foi apoiada pela Universidade Federal do Ceará, Centro Nordestino de Aplicação e Uso da Ressonância Magnética Nuclear (CENAUREMN), Fundação Núcleo de Tecnologia Industrial do Ceará (NUTEC) e financiada pelo Conselho Nacional de Desenvolvimento Científico 
e Tecnológico (CNPq 478488/2013-0) e pela Fundação Cearense de Apoio ao Desenvolvimento Científico e Tecnológico (FUNCAP), Brasil.

\section{REFERÊNCIAS BIBLIOGRÁFICAS}

1. Silva MGS, Ferreira KJN, Teixeira MM, Silva FC, Maciel AP. Estudo de viabilidade técnica da produção de biodiesel de babaçu: uma revisão crítica. Revista da Universidade Vale do Rio Verde. 2014 Ago/Dez;12(2):434-443, doi:10.5892/ruvrd.v12i2.1514.

2. Correia IMS, Araújo GS, Paulo JBA, de Sousa EMBD. Avaliação das potencialidades e características físico-químicas do óleo de girassol (Helianthus annus L.) e coco (Cocos nucifera L.) produzidos no nordeste brasileiro. Scientia Plena. 2014 Mar;10(3):1-7.

3. Dzida M, Jezak S, Sumara J, Zarska M, Góralski P. High pressure physicochemical properties of biodiesel components used for spray characteristics in diesel injection systems. Fuel. 2013 Sep;111:165-171, doi:10.1016/j.fuel.2013.04.031.

4. Lottenberg AMP. Importância da gordura alimentar na prevenção e no controle de distúrbios metabólicos e da doença cardiovascular. Arq Bras Endocrinol Metab. 2009;53(5):595-607.

5. Machado GC, Chaves JBP, Antoniassi R. Composição em ácidos graxos e caracterização física e química de óleos hidrogenados de coco babaçu. Revista Ceres. 2006 Jun/Agos;53(308):463-470.

6. CONAB - Companhia Nacional de Abastecimento. Conjuntura mensal, Babaçu-Amêndoa. Disponível em:<http://www.conab.gov.br/OlalaCMS/uploads/arquivos/14_07_02_16_46_48_babacuamendoamaio 2014.pdf> acessado em 23/11/2015.

7. Carrazza LR, Ávila JCC, Silva ML. Manual tecnológico de aproveitamento integral do fruto e da folha do babaçu. $2^{a}$ edição: Brasília-DF (Brazil); 2012. 32 p.

8. Rodrigues A. Óleo de coco - milagre para emagrecer ou mais um modismo?. ABESO. 2012 Abr;56:5-7.

9. Teixeira MA. Heat and power demands in babassu palm oil extraction industry in Brazil. Energy Conversion and Management. 2005 Aug;46(13-14):2068-2074, doi:10.1016/j.enconman.2004.10.014.

10. Patil TA, Butala DN, Raghunathan TS, Shankar HS. Thermal hydrolysis of vegetable oils and fats.1.reaction kinetics. Ind. Eng. Chem. Res. 1988; 27(5):727-735, doi:10.1021/ie00077a001.

11. Instituto Adolfo Lutz. Métodos físico-químicos para análises de alimentos. 4nd ed. São Paulo (Brasil): IMESP; 2005. Capítulo XVI, Óleos e gorduras; p. 589-625.

12. ABNT - Associação Brasileira de Normas Técnica. NBR-10441: Produtos de petróleo - líquido transparente e opaco - determinação da viscosidade cinemática e cálculo da viscosidade dinâmica, 2007.

13. ASTM - American society for testing and materials. Method D-6304: Determination of water in petroleum products, lubricating oils, and additives by coulometric Karl Fischer titration, 2009.

14. ABNT - Associação Brasileira de Normas Técnica. NBR-14065: Destilado de petróleo e óleos viscoso determinação da massa específica e da densidade relativa pelo densimetro digital, 2009.

15. Baroutian S, Aroua MK, Raman AAA, Shafie A, Ismail RA, Hamdan H. Blended aviation biofuel from esterified jatropha curcas and waste vegetable oils. Journal of the Taiwan Institute of Chemical Engineers. 2013;44(6):911-916, doi:10.1016/j.jtice.2013.02.007.

16. ANVISA - Agência Nacional de Vigilância Sanitária. Resolução RDC n 270, de 22 setembro de 2005. Disponível em: <http//portal.anvisa.gov.br/wps/portal/anvisa/home> acessado em 08/01/2016.

17. Ponte FAF, Maciel IA, Lima MB, Malveira JQ, Albuquerque MCG. Estudo da obtenção de bioproduto via catálise heterogênea. Revista SODEBRAS. 2015;10:116-120.

18. Codex Alimenatrius International Food Standards. Standard for named vegetable oils: Codex Stan 2101999. 2015. Disponível em: <http://www.codexalimentarius.org/standards/list-of-stardards> acessado em 25/11/2015.

19. Oliveira LR, Neves JA, Silva MJM. Avaliação da qualidade físico-química do óleo bruto da amêndoa de babaçu (Orbignya spp). Comunicata Scientiae. 2013; 4(2):161-167.

20. Almoselhy RIM, Allam MH, El-Kalyoubi MH, El-Sharkawy AA. 1H NMR spectral analysis as a new aspect to evaluate the stability of some edible oils. Annals of Agricultural Science. 2014 Dec;59(2):201206, doi: 10.1016/j.aoas.2014.11.006.

21. Da Rós PCM, Silva WC, Grabauskas D, Perez VH, Castro HF. Biodiesel from babassu oil: characterization of the product obtained by enzymatic route accelerated by microwave irradiation. 2014 Jan;52:313-320, doi: 10.1016/j.indcrop.2013.11.013. 